\title{
Comparison of the effects of hyperbaric oxygen and extracorporeal shock wave therapy on healing in osteotendinousjunctional injuries: an experimental study of the rabbit model
}

\author{
Bilgin Halilø, Yüksel Özkan®, Yavuz Akalın๑, Nazan Çevik®, Alpaslan Öztürk® \\ Department of Orthopedics and Traumatology, University of Health Sciences, Bursa Yüksek Ihtisas Training and Research Hospital, \\ Bursa, Turkey
}

\begin{abstract}
Objectives: To biomechanically and histopathologically compare the effects on healing in the osteotendinous region of the treatment methods of hyperbaric oxygen (HBO) and extracorporel shock wave (ESW) on an injury created at the osteotendinous junction in an experimental rabbit model.

Methods: The study included 36 New Zealand rabbits. The patellar tendon tibial osteotendinous junction was cut and then repaired. Group 1 was evaluated as the control group, with no further intervention. In Group 2, a single session of ESW was applied at $14 \mathrm{hz} / 750 \mathrm{Impulse} / 10 \mathrm{mins}$ to an area $1 \times 1 \mathrm{~cm}^{2}$ in the repaired area under fluoroscopy guidance. The animals in Group 3 were applied with $100 \%$ oxygen as HBO at 2.4 ATA/110 min for 7 days. At the end of 6 weeks, 6 animals from each group were applied with a tension test and 6 animals were processed for histopathological examination.
\end{abstract}

Results: In Group 1, the forces at the start of the separation of the osteotendinous junction, at a 2 mm separation and at full rupture were lower than those of Group 2 and Group 3 ( $p=0.001$ and $p=0.001$, respectively). The highest separation force values were determined in Group $3(p=0.001)$. Histopathologically, a statistically significant difference was determined in respect of the fibrocartilage tisssue formation, and fusion with new bone tissue between Group 1 and Group 2 and between Group 1 and Group $3(p<0.05)$. No statistically significant difference was determined between Group 2 and Group $3(p=0.310)$.

Conclusions: It was observed that the application of HBO and ESW improved biomechanical resistance and healing in the injuries in the osteotendinous junction by increasing the bone-tendon fusion in this area. The application of $\mathrm{HBO}$ and ESW increased biomechanical resistance compared to the control group.In the histopathological evaluation, the ESW group was better than the control group and the HBO group was evaluated as the best.

Keywords: Tendon, hyperbaric, oxygen, shock wave, healing

ome studies have reported that the results are not pleasing after surgical interventions of the osteotendinous junctioninjuries. Healing of the osteotendi- nous junction is depend on both the bone and the surrounding soft tissues [1]. Osteotendinous junction injuries are require an aggressive multidisciplinary 
physical therapy and rehabilitation program because of the complex anatomic structure of this region. Failure rates have been reported at 20\%-25\% after rotator cuff repair in the shoulder, and at 10\%-22\% after reconstruction with tendon autograft in anterior cruciate ligament ruptures [2, 3]. For effective and successful treatment, in addition to early surgical intervention;biological orsupplementary treatments are needed to start with an early rehabilitation program that cannot be achieved in routine clinical practice generally.

Biological treatments such as Transforming Growth Factor-beta (TGF-b), Epithelial Growth Factor combined with TGF, Recombinant Human Bone Morphogenic Protein (rhBMP-2), Bone Growth Factor, Granulocyte Colony Stimulating Factor, Periosteal Cells and Autologous Mesenchymal Stem Cells have not routinely applied because of the high costs and difficulties of their acquisition [4, 5-8]. However, supplementary treatments such as Hyperbaric Oxygen Treatment (HBO), Extracorporeal Shock Wave (ESW), Electric Stimulation and Low-intensity Pulsed Ultrasound Stimulation (LIPUS) are currently used in chronic musculoskeletal system diseases [9-13].

Hyperbaric oxygen (HBO) therapy is the inhalation of $100 \%$ oxygen at a pressure of at least 1.4 atmospheres absolute (ATA), $140 \mathrm{kPa}$, in the hyperbaric chamber [1-8]. HBO was first used in decompression sickness [14]. Subsequently, with understanding of the physiological and biomechanical effects, HBO has been widely used in the supplementary treatment for gas embolism, carbonmonoxide poisoning, diabetic foot ulcers, peripheral vascular diseases, thermal burns, skin grafts and flaps, purpura fulminista, osteomyelitis, osteoradionecrosis, cerebral and retinal oedema [15-18].

In the literature, efficacy of ESW has been investigated by both experimental and clinical studies, as a result started to use in chronic musculoskeletal system disorders such as tennis elbow, adhesive capsulitis, heel spur, patellar tendinopathy, Achilles tendinitis, delayed bone union, osteochondritis dissecans and avascular necrosis of the femoral head [19-28].

The aim of this study was examined and compared the effects of HBO and ESW biomechanically and histopathologicallyas a supplementary treatment methods that help to healing of osteotendinous injuryon an experimental rabbit model after surgical intervention.

\section{METHODS}

Approval for this experimental study was granted by the Animal Experiments Local Ethics Committeei. Number of animals was decided with power analysis and a total of 36 adult, female, New Zealand White (Oryctolagus cuniculus L) rabbits weighting mean $3.10 \mathrm{~kg}$ (range, 2.85-3.36) and with a mean age of 6 months with simple randomisation separated into 3 groups as 12 as control group (Group 1), ESW group (Group 2) and HBO group (Group 3) and included in the study.

\section{Surgical Procedure}

Under general anaesthesia, the rabbits insupine position were performed to 5 centimeter $(\mathrm{cm})$ longitudinal incision on the patellar tendon. After exposure of the patellar tendon and the proximal tibia, with 45 degree angle to tibia, a full layer cut was made with a lancet at the bone-tendon junction. Then, immediately below the cut, a tunnel was opened vertical to the tibia long axis, using a $2 \mathrm{~mm}$ drill. The bone junction tendon was anatomically repaired by passing 3.0 prolene sutures through the created tunnel with the Krakow method. To prevent breakage, a quadriceps tenotomy was made to eliminate the extensor power of the quadriceps tendon over the repaired osteotendinous junction. After ensuring the stability of the repaired osteotendinous junction, the layers were anatomically closed [6].

A polyethylene long-leg brace was applied with the hip joint in $30^{\circ}$ flexion, the knee joint in full extension and the ankle free, and thus immobilisation was provided for 6 weeks. In Group 1, as the control group, the repair was made and no additional treatment method was applied. In Group 2, sedation was applied and with an EMD/E 1000 ESW scopy device, a single session of ESW was applied at 14 Hertz (Hz)/750 Impulse/ 1 centimeter.square $\left(\mathrm{cm}^{2}\right) / 10$ minutes (min) to the osteotendinous junction.

The animals in Group 3 were placed in a pressure chamber (Hiperteks Neoks Arbe Chamber) and were applied with $100 \%$ oxygen at 2.4 ATA/110 mins for 1 session each day throughout 7 days.

\section{Biomechanical and Histopathological Evaluation}

At the end of 6 weeks, all animals were sacrifed by same surgical team and samples were separated 
randomly into 2 equal subgroups for biomechanical and histopathological evaluations. Entering over the old incision, the cut was extended proximally and distally and an osteotomy was applied with an osteotome to the centre of the femur and tibia diaphysis. Soft tissues were removed from the patellapatellar tendon-tibia proximal third and the samples were placed in saline and kept at $4^{\circ} \mathrm{C}$ until the biomechanical tests were applied on the same day.

The materials taken for histopathological examination were placed in a sterile dishes in $10 \%$ formaldehyde solution and stored until tested. The whole material was evaluated macroscopically in respect of rupture and separation and the results were recorded. For the biomechanical evaluations, tension tests were applied using an Instron 4301 test device in the Physics Laboratory of the Textile Engineering Department of Uludag University (Fig.1).

The tension test procedure was started at a fixed rate of $25 \mathrm{~mm} / \mathrm{min}$ and was continued. The tension forces (Newton units/kN) were determined at the moment when separation started, when there was a 2 mm separation, and at the moment of complete rupture, and these values were recorded. Histopathological examinations were conducted in the Pathology Laboratory of Uludag University Hospital. After removal of the sutures in the osteotendinous junction area, a longitudinal cut was made from 2 different points and routine follow-up procedures were applied to the two corresponding pieces separately. After the routine procedures, the pieces were embedded in paraffin blocks and sections were cut 4-
5 microns in thickness. These sections were stained with haematoxylene and eosin and evaluated by a pathology specialist blinded to the study. In the histopathological examination, the fibrocartilage tissue, new bone formation and tendon-bone tissue fusion in the healed area of the osteotendinous junction were evaluated using the histological scoring system described by Weng et al. [29]. Each parameter was scored with points.

\section{Statistical Analysis}

Statistical analyzes were carried out with SPSS v.16.0 software (SPSS Inc., IBM Corporation, Armonk, New York, USA) and power analysis was carried out with G-Power v.3.1.9.1 software [Franz Faul, Universitat Kiel, Germany]. For this study, alfa error was accepted as $\% 5$ and $p<0.05$ values were accepted as statistically significant. As there were a total of 3 paired comparisons, Bonferroni correction was applied because of the group analysis, the $p$ value was calculated as $0.05 / 3=0.017$.Before the study, power analysis was performed. Due to similar studiesat the literature statistical power (1- $\beta$ ) was accepted $\% 80$ and total sample size was determined as 36 animals. Demographic datas of rabbits as age and weight were evaluated with the Chi-square test. Because of small sample groups, results were accepted to non-normally distribute so median, minimum and maximum values are determined and non-parametric datas were compared with Kruskal-Wallis and Mann Whitney U-tests.

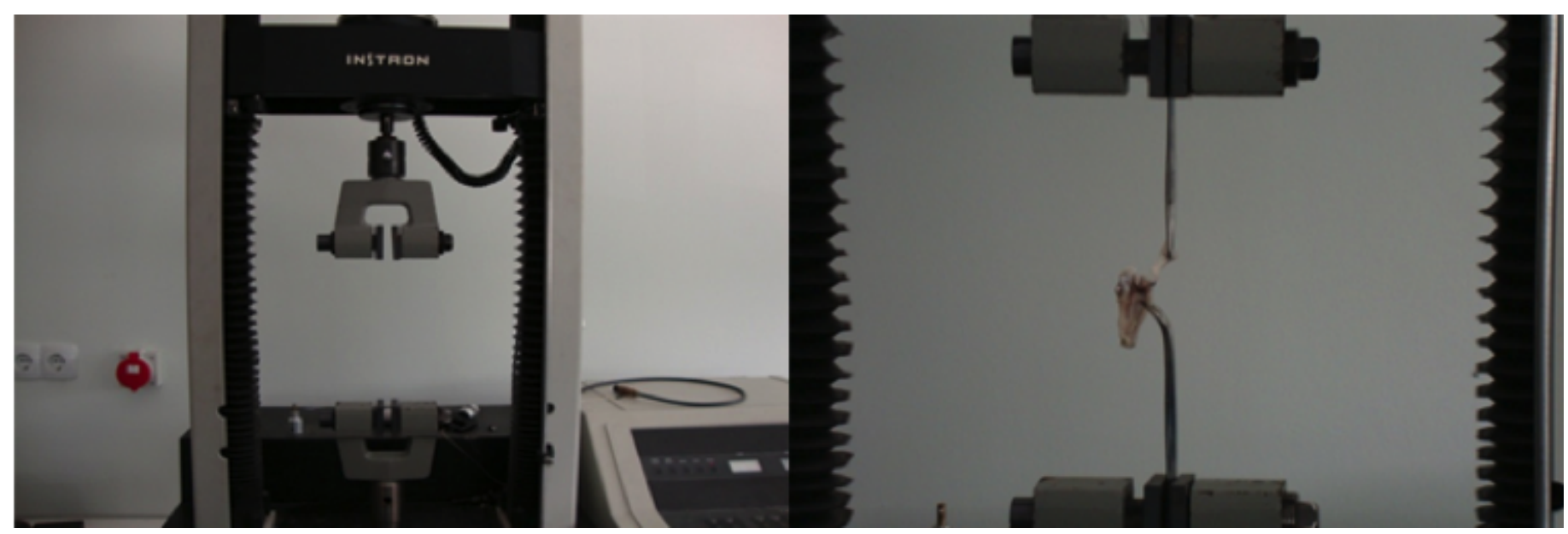

Fig. 1. Application of the tension test with the Universal Instron 4301 test device. 


\section{RESULTS}

A significant difference was observed with comparisons of the force at the start of the separation of the healing area of the osteotendinous junction, the force creating the $2 \mathrm{~mm}$ separation and the force providing full rupture $(p=0.001)$ (Table1).

In Group 1; the separation at the healing area of osteotendinous junction was started first, biomechanical resistance to $2 \mathrm{~mm}$ separation and full rupture were significantly lower than Group 2 and Group 3 ( $p=0.001$ and $p=0.001$, respectively). The highest biomechanical resistance to seperation were determined in Group $3(p=0.001)$ (Table 1).

The fibrovascular tissue, collagen bundles, fibrocartilage tissue and new bone formation were examined in the materials taken from the osteotendinous junction of the other half of the subjects. Fibrovascular tissue and new bone formation were more evident in the treatment groups compared to the control group (Fig. 2a, 2b and 2c). Collagen alignment was more regular and mature in the treatment groups than in the control group. Osteotendinous fusion, fibrocartilage tissue formation, new bone evaluation formation and total histological score were evaluated (Fig. 3a, 3b and 3c). Except fibrocartilage tissue formation $(p=0.049)$; in histological evaluations, there was a statistically significant difference between control group and treatment groups but no difference between treatment groups. (Table 1).

\section{DISCUSSION}

Although osteotendinous junction injuries are often encountered, because of the complex anatomic structure of the region, the expected successful results cannot always be obtained even if early and optimum surgical treatment has been applied [2, 7]. As postoperative immobilisation of the extremity is required and no consensus has yet been reached in literature on the treatment method, there is still not a full understanding of the biomechanical function and histological properties of the anatomic structure of the osteotendinous region and this has rendered treatment of injuries in this region complicated $[1,2]$.

Similarly, in a rabbit model of delayed osteotendinous junction injuries, Qin et al. [12] reported that in the group applied with ESW, there was more bone formation in the healing area of the patellatendon junction at 8 weeks (293.4\%) and 12 weeks $(185.8 \%)$ compared with control group and histologicallycollagen bundles were more mature and fibrocartilage tissue was thicker and more regular. Wang et al. [13] reported that ESW accelerated neovascularisation in the Achilles tendon-bone junction in rabbits and this effect lasted for up to 12 weeks. In those studies, an increase was determined in angiogenc markers in the tissue such as VEGF and endothelial nitric oxide (eNOS).

In an Achilles tendon partial rupture model in rats, Orhan et al. [30] compared subjects applied with ESW $(500$ shock $/ 15 \mathrm{kV})$ with a control group and reported that in the ESW group, neovascularisation was increased, there were fewer adhesions and a mechanically stronger tissue was obtained.

In a patellar tendinitis model created in rabbits by Hsu et al. [31], the application of ESW at $0.29 \mathrm{Mj} / \mathrm{mm}^{2}$ energy was seen to increased collagen synthesis in the healing tissue, acceleratedneovascularisation and increased tensile strength of the tissue. Similar to these findings in literature, accelerated collagen synthesis

Table 1. Biomechanical and histological evaluations

\begin{tabular}{lccccccc}
\hline & Initial Sep. $^{3}$ & 2 mm Sep. $^{4}$ & Full Sep. $^{5}$ & OF $^{6}$ & FTF $^{7}$ & NBF $^{8}$ & TS $^{9}$ \\
\hline K-W $^{1}$ & $\mathbf{0 . 0 0 1}$ & $\mathbf{0 . 0 0 1}$ & $\mathbf{0 . 0 0 1}$ & $\mathbf{0 . 0 1 6}$ & $\mathbf{0 . 0 4 9}$ & $\mathbf{0 . 0 1 6}$ & $\mathbf{0 . 0 1 4}$ \\
MW-U $^{2}$ & & & & & & & \\
Group $1-2$ & $\mathbf{0 . 0 0 2}$ & $\mathbf{0 . 0 0 2}$ & $\mathbf{0 . 0 0 2}$ & $\mathbf{0 . 0 1 5}$ & 0.093 & $\mathbf{0 . 0 1 4}$ & 0.093 \\
Group $1-3$ & $\mathbf{0 . 0 0 2}$ & $\mathbf{0 . 0 0 2}$ & $\mathbf{0 . 0 0 2}$ & $\mathbf{0 . 0 1 5}$ & $\mathbf{0 . 0 2 6}$ & $\mathbf{0 . 0 0 9}$ & $\mathbf{0 . 0 0 2}$ \\
Group $2-3$ & $\mathbf{0 . 0 0 2}$ & $\mathbf{0 . 0 0 2}$ & $\mathbf{0 . 0 0 2}$ & 0.310 & 0.818 & 0.240 & 0.310 \\
\hline
\end{tabular}

${ }^{1}$ Kruskal-Wallis Test, ${ }^{2}$ Mann Whitney-U Test, ${ }^{3}$ Initial Separation $(\mathrm{k} / \mathrm{N}),{ }^{4} 2 \mathrm{~mm}$ Separation $(\mathrm{k} / \mathrm{N}),{ }^{5}$ Full Separatioan $(\mathrm{k} / \mathrm{N}),{ }^{6}$ Osteotendinous Fusion, ${ }^{7}$ Fibrocartilage Tissue Formation, ${ }^{8} \mathrm{New}$ Bone Formation, ${ }^{9}$ Total Score 


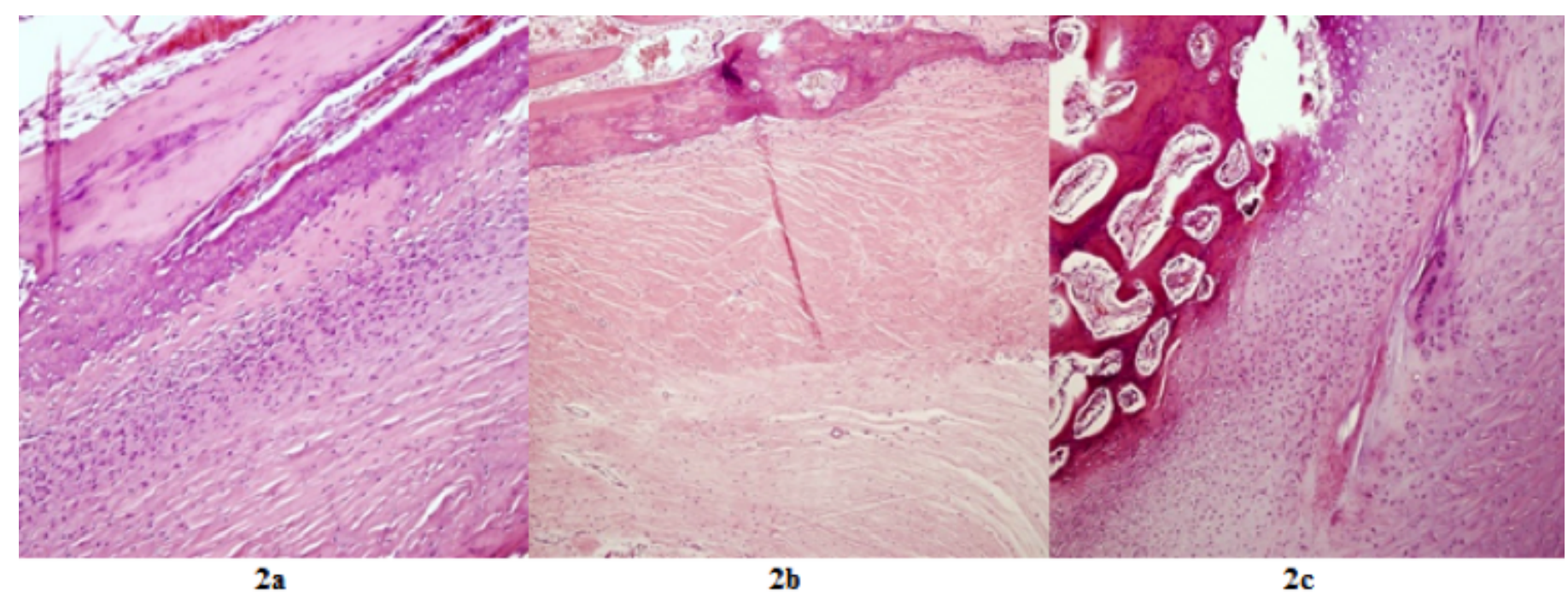

Fig. 2 (a, b and c). Histopathologial examination images of the fibrovascular tissue, collagen bundles, fibrocartilage tissue and new bone formation of the groups.

and maturation;osteotendinous fusion and new bone formation were observed significantly higher in the group 2 (Table 1 and 2) ( $p=0.015$ and $p=0.014)$. As a result of these histological changes, the osteotendinous fusion was increased and biomechanical strength of the tendon was increased.

In the group 3 as the other supplementary treatment method, the biomechanical resistance was determined to be statistically significantly greater than other groups $(p=0.002)$. The results of the histological evaluation showed a similar statistically significant higher osteotendinous fusion and new bone formation but no significant diffirence found at fibrocartilage tissue formation ( $p=0.049)$.

In the literature, several studies were researched to effects of HBO with biological and biomechanical datas and concluded that, $\mathrm{HBO}$ treatment was acceleratedthe fibroblast proliferation,increased the structural protein synthesis, inhibit to TGF- $\beta 1$ synthesis, inhibited the metalloproteinase effects as a result inhibited the degradation also tendon-bone healing and biomechanical strenght of tendon was significantly increased [29, 32, 33].

In the current study, the histopathological and biomechanical findings of the animals applied with supplementary treatments were found statistically

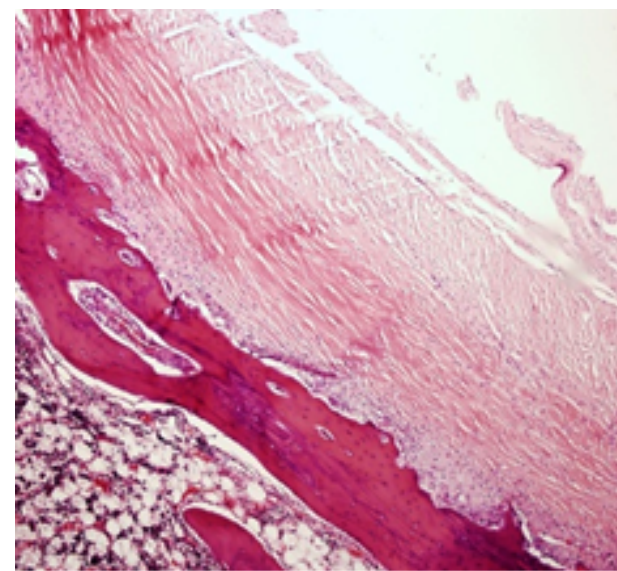

$3 \mathbf{a}$

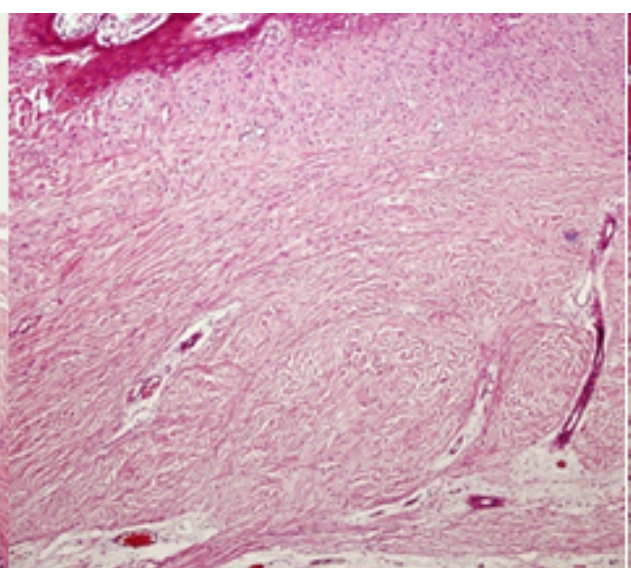

3b

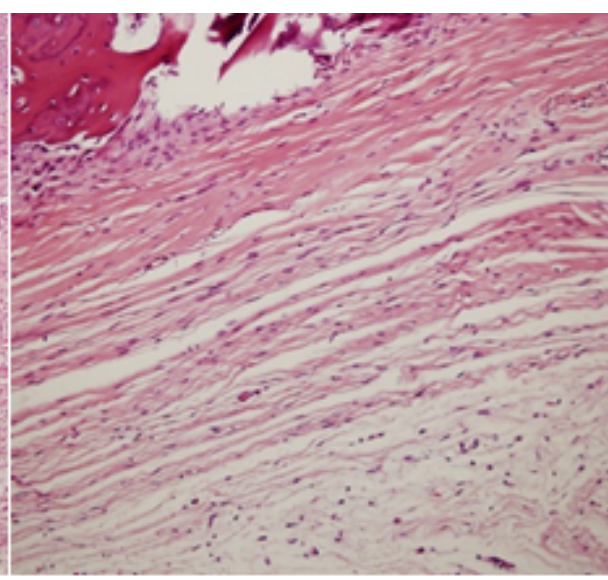

$3 \mathrm{c}$

Fig. 3 ( $a, b$ and c). Histopathologial evaluation images of the collagen alignment and maturation and the formation of fibrocartilage tissue of the groups 
Table 2. Biomechanical results

\begin{tabular}{|c|c|c|c|c|}
\hline & & $\begin{array}{c}\text { Initial Separation } \\
(\mathbf{k} / \mathbf{N})\end{array}$ & $\begin{array}{c}2 \mathrm{~mm} \text { Separation } \\
(\mathrm{k} / \mathrm{N})\end{array}$ & $\begin{array}{l}\text { Full Separation } \\
(\mathbf{k} / \mathbf{N})\end{array}$ \\
\hline \multirow[t]{4}{*}{ Group 1} & $\mathrm{n}$ & 6 & 6 & 6 \\
\hline & Median & 173.50 & 193.00 & 205.50 \\
\hline & Minimum & 168 & 188 & 200 \\
\hline & Maximum & 179 & 199 & 209 \\
\hline \multirow[t]{4}{*}{ Group 2} & $\mathrm{n}$ & 6 & 6 & 6 \\
\hline & Median & 244.50 & 261.50 & 296 \\
\hline & Minimum & 236 & 252 & 288 \\
\hline & Maximum & 252 & 266 & 300 \\
\hline \multirow[t]{4}{*}{ Group 3} & $\mathrm{n}$ & 6 & 6 & 6 \\
\hline & Media & 291 & 326 & 345 \\
\hline & Minimum & 280 & 310 & 330 \\
\hline & Maximum & 296 & 338 & 352 \\
\hline Kruskal-Wallis & $p$ value & 0.001 & 0.001 & 0.001 \\
\hline
\end{tabular}

significant to compared with group1 except fibrocartilage tissue formation (Table 1 and 2). Osteotendinous fusion, new bone formation and biomechanical strenght were observed significantly increased to compared with group $1(p<0.05)$. Comparison between group 2 and 3; the biomechanical strength was significantly increased in group $3(p=0.002)$ but there were no significant difference in histopathological findings $(p>0.05)$.

\section{CONCLUSION}

In conclusion, the results of this study concluded that the supplementary treatmentswere accelerated to healing of osteotendinous junction injuries with increased new boneformation, osteotendinous fusion andbiomechanical strength. Comprasion between ESW and HBO, except the biomechanical strenght was signifcantly increased in $\mathrm{HBO}$; there were significant difference. In the light of these results,
ESW and HBO treatmentscan be considered beneficial in the early postoperative healing of osteotendinous junction injuries and as increasedstrenght of the bonejunction tendon, could make a positive contribution to the rehabilitation process and have a positive effect on outcomes. Also further well-designed randomise clinical trials are required.

\section{Conflict of interest}

The authors disclosed no conflict of interest during the preparation or publication of this manuscript.

\section{Financing}

The authors disclosed that they did not receive any grant during conduction or writing of this study.

\section{REFERENCES}

[1] Galatz LM, Rothermich SY, Zaegel M, Silva MJ, Havlioglu $\mathrm{N}$, Thomopoulos S. Delayed repair of tendon to bone injuries leads to decreased biomechanical properties and bone loss. J 
Orthop Res 2005;23:1441-7.

[2] Lui P, Zhang P, Chan K, Qin L. Biology and augmentation of tendon-bone insertion repair. J Orthop Surg Res 2010;21:59.

[3] Thomopoulos S, Genin GM, Galatz LM. The development and morphogenesis of the tendon-to-bone insertion - what development can teach us about healing. J Musculoskelet Neuronal Interact 2010;10:35-45.

[4] Gulotta LV, Kovacevic D, Ying L, Ehteshami JR, Montgomery S, Rodeo SA. Augmentation of tendon-to-bone healing with a magnesium-based bone adhesive. Am J Sports Med 2008;36:1290-7.

[5] Hashimoto Y, Yoshida G, Toyoda H, Takaoka K. Generation of tendon-to-bone interface "enthesis" with use of recombinant BMP-2 in a rabbit model. J Orthop Res 2007;25:1415-24.

[6] Chen CH, Chen WJ, Shih CH, Yang CY, Liu SJ, Lin PY. Enveloping the tendon graft with periosteum to enhance tendonbone healing in a bone tunnel: A biomechanical and histologic study in rabbits. Arthroscopy 2003;19:290-6.

[7] Sasaki K, Kuroda R, Ishida K, Kubo S, Matsumoto T, Mifune $\mathrm{Y}$, et al. Enhancement of tendon-bone osteointegration of anterior cruciate ligament graft using granulocyte colony-stimulating factor. Am J Sports Med 2008;36:1519-27.

[8] Liu S, Sun Y, Wan F, Ding Z, Chen S, Chen J. Advantages of an attached semitendinosus tendon graft in anterior cruciate ligament reconstruction in a rabbit model. Am J Sports Med 2018;46:3227-36.

[9] Yildiz F, Bilsel K, Pulatkan A, Kapicioglu M, Uzer G, Çetindamar T, et al. Comparison of two different superior capsule reconstruction methods in the treatment of chronic irreparable rotator cuff tears: a biomechanical and histologic study in rabbit models. J Shoulder Elbow Surg 2019;28:530-8.

[10] Qin L, Lu H, Fok P, Cheung W, Zheng Y, Lee K, et al. Low intensity pulsed ultrasound accelerates osteogenesis at bonetendon junction healing. Ultrasound Med Biol 2006;32:1905-11. [11] L Qin, P Fok, H Lu, S Shi, Y Leng, K. Leung Low intensity pulsed ultrasound increases the matrix hardness of the healing tissues at bone-tendon insertion - a partial patellectomy model in rabbits. Clin Biomech (Bristol, Avon) 2006;21:387-94.

[12] Qin L, Wang L, Wong MW, Wen C, Wang G, Zhang G, et al. Osteogenesis induced by extracorporeal shockwave in treatment of delayed osteotendinous junction healing. J Orthop Res 2010;28:70-6.

[13] Wang CJ, Wang FS, Yang KD, Weng LH, Hsu CC, Huang $\mathrm{CS}$, et al. Shock wave therapy induces neovascularization at the tendon-bone junction. A study in rabbits. J Orthop Res 2003;21:984-9.

[14] Başci O, Çimşit M, Zeren S, Saglican Y, Akgün U, Kocaoglu $\mathrm{B}$, et al. Effect of adjuvant hyperbaric oxygen on healing of cartilage lesions treated with microfracture: an experimental study in rats. Undersea Hyperb Med 2018;45:411-9.

[15] Barilaro G, Francesco Masala I, Parracchini R, Iesu C, Caddia G, Sarzi-Puttini P, et al. The role of hyperbaric oxygen therapy in orthopedics and rheumatological diseases. Isr Med Assoc J 2017;19:429-34.

[16] Kuran FD, Pekedis M, Yıldız H, Aydın F, Eliyatkın N. Effect of hyperbaric oxygen treatment on tendon healing after Achilles tendon repair: an experimental study on rats. Acta Orthop
Traumatol Turc 2012;46:293-300.

[17] Demirtaş A, Azboy I, Bulut M, Uçar BY, Alemdar C, Alabalık U, et al. The effect of hyperbaric oxygen therapy on fracture healing in nicotinized rats. Ulus Travma Acil Cerrahi Derg 2014;20:161-6.

[18] Zhao D, Luo S, Xu W, Hu J, Lin S, Wang N. Efficacy and safety of hyperbaric oxygen therapy used in patients with diabetic foot: a meta-analysis of randomized clinical trials. Clin Ther 2017;39:2088-94.e2.

[19] Stasinopoulos D, Johnson MI. Effectiveness of extracorporeal shock wave therapy for tennis elbow (lateral epicondylitis). Br J Sports Med 2005;39:132-6.

[20] Mouzopoulos G, Stamatakos M, Mouzopoulos D, Tzurbakis M. Extracorporeal shock wave treatment for shoulder calcific tendonitis: a systematic review. Skeletal Radiol 2007;36:803-11. [21] Rompe JD, Schoellner C, Nafe B. Evaluation of low-energy extracorporeal shock-wave application for treatment of chronic plantar fasciitis. J Bone Joint Surg Am 2002;84:335-41.

[22] Peers KH, Lysens RJ, Brys P, Bellemans J. Cross-sectional outcome analysis of athletes with chronic patellar tendinopathy treated surgically and by extracorporeal shock wave therapy. Clin J Sport Med 2003;13:79-83.

[23] Orhan Z, Cam K, Alper M, Ozturan K. The effects of extracorporeal shock waves on the rat Achilles tendon: Is there acritical dose for tissue injury? Arch Orthop Trauma Surg 2004;124:631-5.

[24] Lök V, Baloğlu Y, Aydınok H: Experience of shock wave for non-unions in İzmir. In: Coombs R, Schaden W, Zhou S(eds), Musculoskeletal Shockwave Therapy. Greenwich Medical Media Ltd: London, 2000, s:185-6.

[25] Wang CJ. Extracorporeal shockwave therapy in musculoskeletal disorders. J Orthop Surg Res 2012;7:11.

[26] D Agostino MC, Frairia R, Romeo P, Amelio E, Berta L, Bosco V, et al. Extracorporeal shockwaves as regenerative therapy in orthopedic traumatology: a narrative review from basic research to clinical practice. J Biol Regul Homeost Agents 2016;30:323-32.

[27] Carulli C, Tonelli F, Innocenti M, Gambardella B, Muncibì F, Innocenti M. Effectiveness of extracorporeal shockwave therapy in three major tendon diseases. J Orthop Traumatol 2016;17:15-20.

[28] Wang CJ, Wang FS, Huang CC, Yang KD, Weng LH, Huang HY. Treatment for osteonecrosis of the femoral head: comparison of extracorporeal shock waves with core decompression and bone-grafting. J Bone Joint Surg Am 2005;87:2380-7.

[29] Yeh WL, Lin SS, Yuan LJ, Lee KF, Lee MY, Ueng SW. Effects of hyperbaric oxygen treatment on tendon graft and tendon-bone integration in bone tunnel: biochemical and histological analysis in rabbits. J Orthop Res 2007;25:636-45.

[30] Orhan Z, Ozturan K, Guven A, Cam K. The effect of extracorporeal shock waves on a rat model of injury to tendo Achillis. A histological and biomechanical study. J Bone Joint Surg 2004;86:613-8.

[31] Hsu RW, Hsu WH, Tai CL, Lee KF. Effect of shock-wave therapy on patellar tendinopathy in a rabbit model. J Orthop Res 2004;22:221-7.

[32] Kang TS, Gorti GK, Quan SY, Ho M, Koch RJ. Effect of 
Hyperbaric Oxygen on the growth factor profile of fibroblasts. Arch Facial Plast Surg 2004;6:31-5.

[33] Takeyama N, Sakai H, Ohtake H, Mashitori H, Tamai K, Saotome K. Effects of hyperbaric oxygen on gene expressions of procollagen, matrix metalloproteinase and tissue inhibitor of metalloproteinase in injured medial collateral ligament and anterior cruciate ligament. Knee Surg Sports Traumatol Arthrosc 2007;15:443-52. 